\title{
OS REFLEXOS TRIBUTÁRIOS E COMPORTAMENTAIS PROVOCADOS PELA REGULAMENTAÇÃO DA LEI No 13.161/2015 DA DESONERAÇÃO DA FOLHA DE PAGAMENTOS: O CASO DE UMA CONSTRUTORA DO OESTE DO PARANÁ
}

\author{
Aline Favero Castanha ${ }^{1}$ \\ Neiva Feuser Capponi ${ }^{2}$
}

CASTANHA, A. F.; CAPPONI, N. F. Os reflexos tributários e comportamentais provocados pela regulamentação da lei $\mathrm{n}^{\circ} 13.161 / 2015$ da desoneração da folha de pagamentos: o caso de uma construtora do oeste do Paraná. Rev. Ciênc. Empres. UNIPAR, Umuarama, v. 20, n. 1, p. 107-129, jan./jun. 2019.

RESUMO: Diante do cenário de crise econômica nacional, o Governo Federal promoveu a alteração na legislação da desoneração da folha de pagamentos, com o intuito de equilibrar as contas públicas. Dessa maneira, o trabalho avaliou como a desoneração da folha de pagamentos alterou o custo do departamento de pessoal, e se a variação do quadro funcional se deu devido à alteração no custo com a folha de pagamentos ou a fatores comportamentais dos colaboradores e gestores de uma microempresa do ramo da construção civil, da região Oeste do Paraná. O período analisado compreende dados de 2012 a 2015, período de vigor da Lei $\mathrm{n}^{\mathrm{o}}$ 12.546/2011 que regulamentou a desoneração e de 2016, com alteração dada pela Lei $n^{\circ} 13.161 / 2015$. Para tanto, buscou-se os dados da empresa nos relatórios e demonstrativos contábeis, que, por meio da análise de conteúdo de entrevistas pode-se verificar o meio menos oneroso para o recolhimento da contribuição previdenciária patronal, a variação do quadro funcional e o motivo pelo qual ocorreu. O resultado evidenciou que a empresa, objeto de estudo, não foi beneficiada pela medida de desoneração da folha de pagamentos e, por meio da análise das entrevistas, constatou-se que a variação do quadro funcional não foi influenciada pela legislação vigente nem pelo comportamento dos indivíduos, bem como que o comportamento é fator de grande relevância para a permanência no quadro de funcionários ativos.

PALAVRAS-CHAVE: Desoneração da folha de pagamentos; Quadro funcional; Comportamento.

DOI: $10.25110 /$ receu.v20i1.7085

${ }^{1}$ Bacharel em Ciência Contábeis pela UNIOESTE, Campus de Cascavel - PR, e-mail: ali_casatanha@hotmail.com

${ }^{2}$ Professora no curso de Ciências Contábeis na UNIOESTE, Campus de Cascavel - PR, e-mail: nfcapponi@hotmail.com 


\title{
TAX AND BEHAVIORAL REFLEXES CAUSED BY THE REGULATION OF LAW 13.161/2015 ON THE PAYROLL TAX EXEMPTION: THE CASE OF A CONSTRUCTION COMPANY IN WESTERN PARANÁ
}

\begin{abstract}
In face the national economic crisis scenario, the federal government promoted a change in the legislation related to the payroll tax exemption in order to balance the public accounts. Thus, the objective of the study is to evaluate how payroll tax exemption has changed the cost of the human resources department, and whether the change in staff was due to the change in payroll costs or the behavioral of employees and managers of a microenterprise in the civil construction industry. The period analyzed comprises the enforcement of Law $12.546 / 2011$, which regulated the payroll tax exemption (2012 to 2015), and the amendment brought by Law 13.161/2015 (2016). Therefore, the authors referred to the company's actual data in the accounting reports and balance statements, and by analyzing their content, the authors were able to identify the least costly means for the collection of the employer's social security contribution, the change in staff and the reason why such change occurred. The result showed that the company under study was not benefited by the payroll tax exemption measure and, through the analysis of interviews, it verified that the staff variation was not influenced by the current tax legislation or even by the individuals' behavior, and that the behavior is a factor of great relevance for the permanence in the active staff.
\end{abstract}

KEY WORDS: Payroll tax exemption; Staff; Behavior.

\section{LOS REFLEJOS TRIBUTARIOS Y COMPORTAMENTALES PROVOCADOS POR LA REGLAMENTACIÓN DE LA LEY No 13.161 / 2015 DE LA EXONERACIÓN DE LA NÓMINA DE PAGOS: EL CASO DE UNA CONSTRUCTORA DEL OESTE DE PARANÁ}

RESUMEN: Ante el escenario de crisis económica nacional, el Gobierno Federal promovió la modificación en la legislación de la exoneración de la nómina, con el fin de equilibrar las cuentas públicas. Así, la investigación evaluó cómo la exoneración de la nómina de pagos alteró el costo del departamento de personal, y si la variación del cuadro funcional se dio debido a la alteración en el costo con la nómina de pagos o a factores conductuales de los colaboradores y gestores de una microempresa de construcción civil, de la región Oeste de Paraná. El período analizado comprende datos de 2012 a 2015, período de vigencia de la Ley $\mathrm{n}^{\circ} 12.546$ / 2011 que reglamentó la exoneración y de 2016, con alteración dada por la Ley ${ }^{\circ} 13.161$ / 2015. Para ello, se buscó los datos de la empresa en 
los informes y demostrativos contables, que, por medio del análisis de contenido de entrevistas, se puede verificar el medio menos oneroso para recaudación de la contribución de la seguridad social patronal, la variación del cuadro funcional y el motivo por lo que ocurrió. El resultado evidenció que la empresa, objeto de estudio, no fue beneficiada por la medida de exoneración de la nómina de pagos y, por medio del análisis de las encuestas, se constató que la variación del cuadro funcional no ha sido influenciada por la legislación vigente ni por el comportamiento de los individuos, así como que el comportamiento es factor de gran relevancia para la permanencia en el cuadro de funcionarios activos.

PALABRAS CLAVE: Exoneración de la nómina de pagos; Cuadro funcional; Comportamiento.

\section{INTRODUÇÃO}

A seguridade social é citada no Artigo 194 da Constituição Federal de 1988 como sendo um conjunto integrado de ações de iniciativa dos poderes públicos e da sociedade, destinadas a assegurar os direitos relativos à saúde, à previdência e à assistência social (BRASIL, 1988). O artigo 195 define que, de forma direta ou indireta, a seguridade social será financiada mediante recursos provenientes dos orçamentos da União, dos Estados, do Distrito Federal e dos Municípios, e das contribuições sociais, advindas dos empregadores e empregados. Em vista disso, os valores são destinados aos cofres do Instituto Nacional de Seguridade Social (INSS), entidade responsável pela manutenção da subsistência de trabalhadores incapacitados de exercer suas atividades laborativas e dos dependentes.

Em 2011, mediante as reinvindicações do setor empregatício, o Governo Federal implantou a desoneração da folha de pagamentos para alguns setores por meio da Lei $\mathrm{n}^{\circ} 12.546$. Esta medida visou reduzir o custo do empregador com a seguridade social alterando a incidência das contribuições previdenciárias devidas pela empresa (BRASIL, 2011). Portanto, os empregadores deixaram de recolher a contribuição previdenciária patronal de $20 \%$ sobre o total da folha de pagamentos para recolher a contribuição previdenciária de $1 \%$ ou $2 \%$ sobre a receita bruta, sendo o percentual definido de acordo com a atividade preponderante.

Zanghelini, Braga e Maçaneiro (2015) afirmam que a medida tomada pelo Governo Federal reduziu os custos dos empregadores com a folha de pagamentos. Entretanto, a desoneração causou um déficit de cifras orçamentárias da ordem de três dezenas de bilhões de reais por ano, sendo o Tesouro Nacional obrigado a compensar a Previdência Social pelas perdas. Mediante a escassez de recursos para a manutenção das atividades de seguridade social, buscou-se medi- 
das para equilibrar as contas públicas, sancionando um projeto de Lei, revendo a desoneração da folha de pagamentos. Ao instituir a Lei n ${ }^{\circ}$ 13.161/2015 propiciou a alteração dos percentuais de contribuição para 1,5\%, 2,5\%, 3,0\% e 4,5\% sobre a receita bruta, também deu a opção pela desoneração, podendo ocorrer sobre a contribuição previdenciária patronal sobre a folha de pagamentos ou sobre o total da receita bruta (BRASIL, 2015).

Mas, a Medida Provisória ${ }^{0} 774 / 2017$ restringiu as atividades aptas à opção pela desoneração da folha. Toda esta dinâmica ainda não foi capaz de sanar ou atenuar o problema do desemprego. As contratações e as demissões de empregados dependem de outros fatores, como o aumento da demanda, de crédito disponível, melhoria das taxas de juros, uma vez que não é papel da previdência social a geração de empregos (KERTZMAN, 2012). Não só o aspecto tributário causa impacto em uma organização, mas também o sistema social, que é um item de relevância, que tem a mesma ou mais influência sobre o desempenho da entidade. Segundo Skinner (1978), o estudo científico do comportamento aperfeiçoa e completa esta experiência comum, quando demonstra de forma mais precisa as relações entre circunstâncias e comportamentos.

O estudo de Tavares, Orlando e Sueth (2014) discutiu os tipos de conflitos que podem se manifestar no relacionamento profissional entre o engenheiro civil e seus colaboradores, por ocasião da prática de gestão de pessoas no canteiro de obras, no contexto de construção civil. Entre os achados obtidos, constata-se que situações conflitivas se estabelecem por consequência da direção de tarefas ou orientação técnica do engenheiro aos seus subordinados na cadeia hierárquica durante a execução dos projetos. $\mathrm{O}$ estudo evidenciou que muitos dos conflitos são gerados pela má gestão, sendo que os gestores não sabem gerir o comportamento dos colaboradores. Nesse contexto, as admissões e demissões nas organizações podem ser explicadas pela Teoria Comportamental, na qual Spector (2006) salienta a importância de o gestor compreender o comportamento individual do funcionário e aumentar o bem-estar dele no ambiente de trabalho.

O ramo da construção civil, com a alteração da legislação da desoneração da folha de pagamentos, poderá ser influenciado direta ou indiretamente, tendo em vista a importância deste ramo para a economia do país, que gera cerca de $6,5 \%$ do Produto Interno Bruto (PIB) do Brasil, e emprega diretamente mais de três milhões de pessoas. Cabe ressaltar que a rentabilidade do setor caiu de $11,2 \%$ em 2013 para 2,3\% em 2014, e que apenas 23 empresas entre as 500 maiores do país, conseguiram crescer no ano de 2014 (AMORIN, 2015). Segundo Cataldo (2016), aproximadamente 500 mil trabalhadores do ramo da construção civil foram demitidos até o início de 2016.

Dessa maneira, ressalta-se que a desoneração da folha de pagamentos é um tema atual, em constante discussão e com alteração recente em lei. Justifi- 
ca-se o presente trabalho pela necessidade de verificação, se com a regulamentação da Lei $n^{0} 13.161 / 2015$ a realidade apresentada por Nardelli, Terres e Fidelix (2013) e Costa, Paixão e Aguiar (2015) de que apenas empresas de grande porte são beneficiadas pela desoneração, e, ainda, se o impacto positivo no índice de empregabilidade no ramo da construção civil apresentado por Ludwig, Borgert e Kremer (2015) se manteve. Justifica-se ainda, quanto ao conhecimento do profissional contábil quanto às discussões que estão em voga. Portanto, a análise do planejamento tributário é crucial para identificar se a opção pela desoneração da folha de pagamentos é vantajosa para a construtora, objeto de estudo, e ainda, identificar se a variação no quadro funcional se deu devido à nova legislação ou por fatores comportamentais dos colaboradores e gestores.

O presente trabalho foi orientado pela seguinte questão: como a desoneração da folha de pagamentos alterou o custo do departamento de pessoal, e se a variação do quadro funcional se deu devido à alteração no custo com a folha de pagamentos ou a fatores comportamentais dos colaboradores e gestores de uma microempresa do ramo da construção civil?

Na realização do estudo foram coletados dados de 2012 a 2016, posteriormente foi realizada uma comparação entre o período de vigor da Lei ${ }^{\circ}$ 12.546/2011, que instituiu a obrigatoriedade da desoneração da folha de pagamentos em relação à Lei ${ }^{0} 13.161 / 2015$, que regulou a possibilidade de opção pela desoneração.

\section{REVISÃO DA LITERATURA}

\subsection{Papel da previdência social e cálculo das contribuições}

Para a discussão dos custos da folha de pagamentos, mais precisamente do custo que a contribuição previdenciária patronal gera às empresas, é necessário realizar uma contextualização a respeito do órgão público que gerencia estes valores, a Previdência Social, a obrigatoriedade do pagamento e a forma e base de cálculo deste imposto.

A Previdência Social é um seguro social, financiado por contribuições previdenciárias que objetiva a proteção social aos cidadãos contribuintes. O artigo $1^{\circ}$ da Lei $n^{\circ} 8.213 / 1991$ estabelece que a Previdência Social tem por fim assegurar a remuneração do contribuinte por motivo de incapacidade, desemprego involuntário, idade avançada, tempo de serviço, encargos familiares e prisão ou morte daqueles de quem dependiam economicamente (BRASIL,1991).

Assim, a Previdência Social se torna responsável pela subsistência do trabalhador e dos dependentes no período em que este se encontra impossibilitado de realizar atividades remuneradas devido sua contribuição no período em que esteve ativo (PREVIDÊNCIA SOCIAL, 2013). A Previdência Social 
é de filiação obrigatória e possui caráter contributivo, ou seja, todo o cidadão que exerce atividade remunerada, inclusive os que já são aposentados, deverão obrigatoriamente contribuir para a Previdência Social, sendo denominada como Contribuição Previdenciária. Para os trabalhadores, a contribuição é descontada em folha de pagamento, e seu percentual varia de acordo com a faixa salarial que percebe.

Para o empregador, a contribuição previdenciária se dá pela aplicação do percentual de $20 \%$ sobre o total da folha de pagamentos, acrescido do valor do Seguro Acidente de Trabalho (RAT), que será de 1\%, 2\% ou 3\%, Fator Acidentário de Prevenção (FAP), que varia de 0,5000 a 2,000 e Terceiros de 5,8\% (RECEITA FEDERAL DO BRASIL, 2016).

Com a desoneração da folha de pagamentos, instituída pela Lei $\mathrm{n}^{\circ}$ 12.546/2011, a contribuição previdenciária patronal para alguns setores da economia passou a ser calculada sobre a receita bruta. Desta forma, a apuração desta receita, que será base para o cálculo da contribuição previdenciária, será obtida pela receita advinda da venda de bens nas operações de conta própria, da prestação de serviços em geral e do resultado obtido nas operações de conta alheia (BRASIL, 2011). A Lei $n^{\circ} 12.546 / 2011$ alterou o modo de cálculo da contribuição previdenciária patronal, antes era calculado um percentual sobre o total da folha de pagamentos, a partir da nova Lei passou a ser calculado um percentual sobre o faturamento da entidade.

\subsection{Desoneração da folha de pagamentos}

O Governo Federal lançou em 2011 o Plano Brasil Maior com o objetivo de incentivar a inovação tecnológica, aumentar a competitividade da indústria nacional e estimular as exportações. Entre as medidas propostas, estava a desoneração da folha de pagamentos para as empresas que empregam um elevado número de trabalhadores do país, por meio da Medida Provisória n ${ }^{\circ} 540$ de 02 de agosto de 2011 (BRASIL, 2011). Em 14 de dezembro de 2011, esta medida provisória foi convertida na Lei ${ }^{\circ} 12.546$ instituindo a Contribuição Previdenciária Substituta, que altera as bases e percentuais de cálculo da contribuição previdenciária (BRASIL, 2011). Desta forma, a desoneração da folha de pagamentos tem o objetivo de reduzir os encargos sobre a folha de pagamentos, deixando de recolher o percentual de $20 \%$ sobre a folha de pagamentos para recolher um percentual sobre o total da receita bruta operacional, excluindo as vendas canceladas e os descontos incondicionais concedidos.

Contudo, o aumento do custo das empresas com os encargos trabalhistas pode ou não propiciar a redução de novas contratações, o aumento de demissões e, também, a inadimplência dos empregadores para com a Previdência Social. Entretanto, a desoneração não se tornou obrigatória para todas as empresas, 
apenas para alguns serviços específicos.

A medida adotada influenciou na redução da arrecadação da contribuição previdenciária patronal, causando um déficit na previdência social, o que exigiu que o Governo Federal buscasse medidas que aumentassem as alíquotas de recolhimento, particularmente, por meio de alteração do conteúdo da legislação original. Em 2015, o Governo Federal anunciou a Medida Provisória n ${ }^{\circ} 669$, que apresentava intenções em alterar as alíquotas da contribuição previdenciária sobre o lucro bruto. Ainda, mostrava-se a possibilidade de revogação da obrigatoriedade da desoneração da folha de pagamentos. Posteriormente, em 31 de agosto de 2015, a medida provisória supramencionada foi convertida na Lei $\mathrm{n}^{\mathrm{o}}$ 13.161, alterando, portanto, a Lei $\mathrm{n}^{\circ} 12.546 / 2011$.

Com a aprovação da Lei $\mathrm{n}^{\circ} 13.161 / 2015$ a desoneração da folha de pagamentos passou a ser opcional, devendo a empresa fazer a opção pela tributação no início de cada exercício ou, a primeira competência subsequente para a qual haja receita bruta apurada, mediante o pagamento da contribuição previdenciária substituta. A opção é irretratável para todo o ano calendário (BRASIL, 2015). Desta forma, as empresas que optam pela desoneração da folha de pagamentos utilizam uma alíquota de recolhimento maior, sendo que as alíquotas de $1 \%$ e $2 \%$ alteraram-se para 2,5\% e 4,5\%, respectivamente (BRASIL,2015).

Para Ribeiro (2013), a desoneração da folha de pagamentos reduziu a carga tributária sobre a folha de pagamentos para empresas que não apresentam uma constante oscilação no faturamento, pois quanto maior o faturamento maior o valor da contribuição previdenciária.

O problema da desoneração da folha de pagamentos está no fato de que o total da folha de pagamentos e o total da receita bruta apresentam uma enorme disparidade, causando, assim, uma desigualdade de benefícios entre as empresas de mesma atividade econômica.

A opção pela contribuição previdenciária sobre a receita bruta é vantajosa quando o valor da base de cálculo dos $20 \%$ (folha de pagamentos) corresponde, no mínimo, a 22,5 do faturamento do mês. Todavia, com o aumento da alíquota de $2 \%$ para $4,5 \%$ a economia seria próxima a $10 \%$, e não seria vantajosa a opção pela desoneração da folha de pagamentos (BAIÃO, 2016). Caso que se aplica ao ramo da construção civil, que se optante pela desoneração da folha de pagamentos, deverá efetuar o cálculo da contribuição previdenciária patronal utilizando a alíquota de $4,5 \%$.

Tendo em vista a importância do ramo da construção civil, que está num momento de retratação perante a economia do país, o elevado número de demissões no período e a alteração dada no percentual de recolhimento da contribuição previdenciária patronal, faz-se necessário à sua contextualização. 


\subsection{Relevância econômica e social da construção civil e a gestão de pessoas no ramo em período de crise}

O ramo da construção civil é um setor que se relaciona direta ou indiretamente com outros setores da economia, pois demanda de uma elevada quantidade de insumos no processo produtivo, além de empregar um elevado número de pessoas. De acordo com Maia (2001), a construção civil é um ramo que possui características descentralizadas e possui caráter nômade e com produtos únicos. Logo, o produto da construção civil se apresenta como um bem de grande valor de aquisição e diferente em cada obra executada (MORAIS,2007).

Já Oliveira (2011), afirma que a este ramo se agrega a prioridade na alocação dos recursos escassos da economia e o fortalecimento social, devido ao fato de gerar uma grande demanda de mão de obra. Ainda, segundo o autor, o ramo da construção civil relaciona as atividades de preparação de terrenos, as obras de edificações e de engenharia civil, as instalações de materiais e equipamentos necessários ao funcionamento dos imóveis e as obras de acabamentos, bem como reformas em edificações existentes. Por não ter um local fixo para a execução dos trabalhos, cada contrato firmado exige um objeto e mão de obra flexível.

O setor da construção civil possui um elevado uso de mão de obra, o que faz com que os custos relacionados à folha de pagamentos ultrapassem $30 \%$ do total dos custos e $24,7 \%$ da receita bruta (IBGE, 2012). Segundo Carvalhães (2015), com a Lei n ${ }^{\circ}$ 13.161/2015 a desoneração da folha de pagamentos não será benéfica no caso de construtoras que terceirizam toda a mão de obra de execução, ou no caso de construtoras que, também, são incorporadoras, nas quais a contribuição substitutiva incide sobre a receita da venda de imóveis, além da venda de serviços. Contudo, a autora ainda ressalta que tornar a desoneração da folha de pagamentos opcional trouxe inúmeras vantagens para o ramo da construção civil.

O setor tem um ritmo de trabalho acelerado e o uso da mão de obra é extenuante, esses fatores acarretam problemas com relação à gestão de pessoas (FARRAH, 1996). Isso deve gerar melhores políticas de gestão de pessoas, pois empresas que investem em modelos de gestão de pessoas, de acordo com Byrom e Brandenburg (2006), têm conseguido obter altos níveis de produtividade, desempenho, eficiência nos custos e eficácia global da empresa.

Diante disso, cabe a realização da contextualização em relação à teoria comportamental aplicada ao setor da construção civil.

\subsection{Aplicação da teoria comportamental no ramo da construção civil}

Nas organizações, os gestores devem manter um equilíbrio comportamental entre os membros da equipe de trabalho, pois a harmonia organizacional propicia que todos se empenhem para atingir as metas e objetivos traçados. Para 
um colaborador é muito importante ser reconhecido para poder sentir-se peça fundamental no processo produtivo. Desta forma, é importante que o gestor adote uma cultura interna, no que diz respeito ao tratamento dos seus profissionais, elegendo medidas para que esses percebam que são integrantes essenciais da equipe. De acordo com Chiavenato (2009), mesmo sendo as pessoas recursos às organizações, estas são portadoras de características genéticas pessoais. Quando isso é assimilado à compreensão quanto ao comportamento humano nas organizações, torna-se melhor.

Segundo Robinns (2005), o estudo do comportamento visa verificar o que as pessoas fazem nas organizações e como este comportamento influencia no desempenho do todo. Contudo, a teoria comportamental refere-se ao desenvolvimento e à aplicação de princípios científicos no ambiente de trabalho (SPECTOR, 2006). Tendo como foco principal a análise da natureza de uma atividade, a solução de um problema organizacional, verificação dos sentimentos e opiniões dos funcionários, avaliação do desempenho dos funcionários, seleção de funcionários, execução de programas de treinamento e avaliação da eficácia deste desenvolvimento de testes psicológicos e implementação de mudanças organizacionais.

Como em muitos casos, os gestores não veem os colaboradores como pessoas, conforme sugere Chiavenato (2009), esses são considerados apenas ferramentas essenciais para a conclusão de obras e, depois de concluído o serviço, tornam-se itens descartáveis no processo produtivo. Além disso, não há como falar em qualidade e produtividade se o atendimento básico não é ofertado, a motivação dos operários tem como fatores básicos, a segurança no trabalho, condições mínimas de higiene e alimentação digna (HEINECK, 1991).

A nova realidade do setor da construção civil, ou seja, a falta de operários qualificados remete à concepção de que é necessária a preocupação com as pessoas que fazem parte dos processos produtivos, porque, caso não seja dada a atenção necessária os gestores os perderão (HERNANDES, 2002). Cabe considerar que, como na construção civil, o objeto é a obra finalizada, os colaboradores são peças fundamentais para esta concretização e são considerados como itens de competividade nesta indústria de resultados. Sendo esses, as peças fundamentais para o alcance de metas e para o crescimento da empresa. Daí a necessidade de o comportamento desses, estar sempre motivado.

Segundo Chiavenato (2008), é de suma importância tirar das pessoas o estigma de fornecedoras de mão de obra para fornecedoras de conhecimento, é a revolução que empresas bem-sucedidas estão fazendo. Isso gera uma nova cultura e estrutura organizacional que privilegia o capital humano e o valor que só as pessoas podem proporcionar, desde que devidamente motivadas. Tavares, Longo e Sueth (2014) salientam que a gestão de pessoas no canteiro de obras, 
muitas vezes, é realizada pelo engenheiro civil e afirmam que a convivência profissional entre trabalhadores atende às necessidades ao se considerar o ambiente de trabalho como um sistema de troca de valores que acaba por tornar-se uma variável fundamental, responsável por estabelecer uma harmonização entre os integrantes da empresa e contribui para o estabelecimento de um clima de estabilidade organizacional.

Diante do exposto, estabelece-se a metodologia da pesquisa que auxiliou na resolução da questão exposta, alinhada com as limitações enfrentadas no estudo e forma de coleta de dados, que objetivaram os resultados pretendidos com este trabalho.

\section{METODOLOGIA}

O presente estudo classifica-se quanto aos objetivos como pesquisa explicativa, uma vez que para Gil (2007), este tipo de pesquisa preocupa-se em identificar os fatores que determinam ou que contribuem para a ocorrência dos fenômenos. Em relação aos procedimentos, a pesquisa se classifica como estudo de caso, uma vez que esta modalidade auxiliou a verificação dos reflexos da Lei $\mathrm{n}^{\mathrm{o}} 13.161 / 2015$ da desoneração da folha de pagamentos no custo com a previdência social e no quadro funcional, e se a variação do quadro funcional se dá devido ao fator comportamental do colaborador e gestor da empresa, objeto de estudo, sendo analisado o caso específico de uma construtora localizada na região Oeste do Paraná. Quanto à abordagem do problema foi utilizada a pesquisa qualitativa.

Diante do exposto, e orientada pelos estudos de Ludwig, Borgert e Kremer (2015), a pesquisa foi orientada pelas seguintes hipóteses:

a) hipótese A: a Lei $n^{0} 13.161 / 2015$ da desoneração da folha de pagamentos reduziu o custo com o departamento de pessoal da empresa objeto de estudo;

b) hipótese B: a variação do quadro funcional não foi influenciada exclusivamente pela alteração da Lei.

O estudo de caso utilizou múltiplas fontes de evidência e dados que permitiram diferentes observações dos participantes no estudo. Assim, para a coleta de dados da construtora, foi utilizada como instrumento de pesquisa a análise documental de relatórios por meio do Demonstrativo do Resultado do Exercício (DRE), do total da remuneração dos empregados e diretores, pelo resumo analítico da folha de pagamentos, e, informações transmitidas ao Cadastro Geral de Empregados e Desempregados (CAGED) para a análise da variação do quadro funcional. Esta análise permitiu uma verificação mais aprofundada da variação dos valores recolhidos a título de contribuição previdenciária patronal.

Como instrumento de pesquisa também foram utilizadas as entrevistas 
semiestruturadas, as quais foram elaboradas, conforme observações pertinentes ao estudo, com questões abertas, sendo direcionadas ao responsável do departamento de pessoal e gerente operacional, com o intuito de analisar as percepções dos mesmos em relação à desoneração da folha de pagamentos, alteração no custo com o departamento de pessoal, variação do quadro funcional e as variáveis comportamentais dos colaboradores e gestores.

$\mathrm{O}$ estudo apresenta limitações quanto às entrevistas, pois dados importantes podem ter sido retidos pelos respondentes levando à falsas interpretações. Outra limitação da pesquisa é o impedimento de generalização dos resultados obtidos, uma vez que esses são resultantes do estudo em uma construtora específica e as diferentes formas de administração quanto às demais construtoras não permite a utilização dos mesmos resultados para outros casos. Além disso, os resultados obtidos tornam-se exclusivos para o período de análise da pesquisa, pois em outros períodos podem ocorrer mudança de gestão, remanejamento de funcionários e alteração de faturamento e alíquota de recolhimento, o que não garante a permanência das mesmas percepções em vista dos reflexos tributários e comportamentais causados pela Lei $n^{0} 13.161 / 2015$ da desoneração da folha de pagamento.

Por fim, deve-se evidenciar a limitação em relação à legislação vigente que trata da desoneração da folha de pagamentos, a qual pode ser revogada ou alterada a qualquer momento, proporcionando o obsoletismo do presente estudo.

\section{RESULTADOS E DISCUSSÃO}

\subsection{Percepção dos entrevistados em relação à desoneração da folha de pa- gamentos}

A empresa foi constituída em 31 de julho de 2008 e, apresenta como atividade preponderante, a construção de edifícios, está localizada na cidade de Cascavel, no estado do Paraná. O quadro funcional é composto por 14 colaboradores que recebem uma média salarial de $\mathrm{R} \$ 1.748,00$ distribuídos entre os cargos de serventes, oficiais e mestres de obra.

O quadro societário é composto por três pessoas e permanece inalterado desde a abertura, sendo que a administração, a gestão de pessoal e o controle operacional são realizados pelos sócios. A construtora é considerada uma microempresa e é tributada pelo regime do lucro presumido e a contabilidade é realizada por um escritório terceirizado.

As entrevistas foram aplicadas para duas pessoas. A primeira entrevista foi uma das sócias da empresa, a qual é responsável pelo departamento de pessoal. Ela possui formação acadêmica em secretariado executivo e realiza esta função há sete anos na construtora, mas já havia auxiliado no gerenciamento de 
pessoal e na administração em outra entidade. O outro entrevistado foi o sócio responsável pelo gerenciamento operacional. Ele não possui formação acadêmica, mas possui cursos na área de construção civil e experiência prática do cotidiano dos canteiros de obra.

Ao questionar os gestores quanto à sua percepção em relação à desoneração da folha de pagamentos, ambos afirmaram que ela é benéfica para algumas empresas, enquanto para outras não, conforme figura1.

Figura 1: Percepção quanto à desoneração da folha de pagamentos

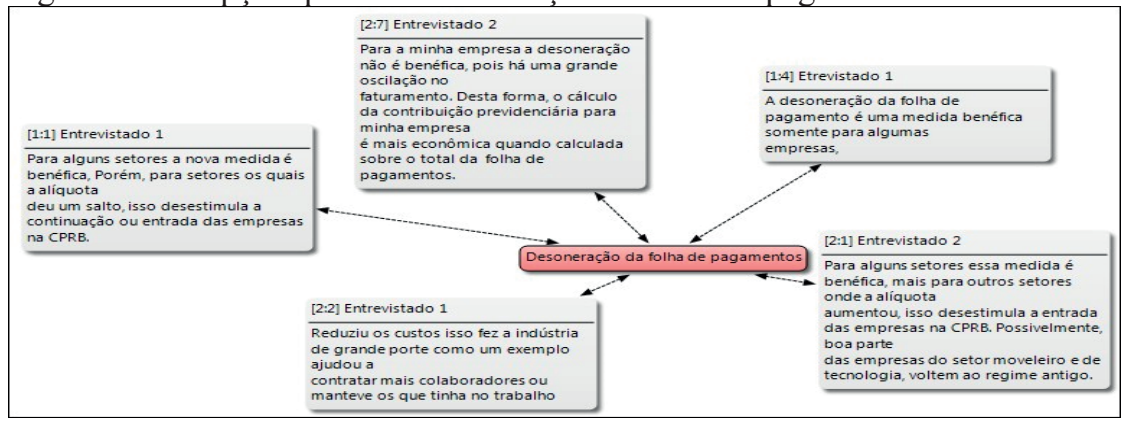

Fonte: Elaborado pelos autores, 2017.

Na concepção do entrevistado 1 , a desoneração da folha de pagamentos reduziu os custos da indústria de grande porte e ajudou na contratação de mais colaboradores ou na manutenção dos que já integravam o quadro funcional. No entanto, o entrevistado 2 evidencia que a desoneração não foi benéfica para a empresa objeto de estudo, pois ela apresenta uma oscilação no faturamento conforme dados do DRE e resumo analítico da folha de pagamentos demonstrados no figura 1 .

Figura 2: Total anual das bases de cálculo da contribuição previdenciária patronal

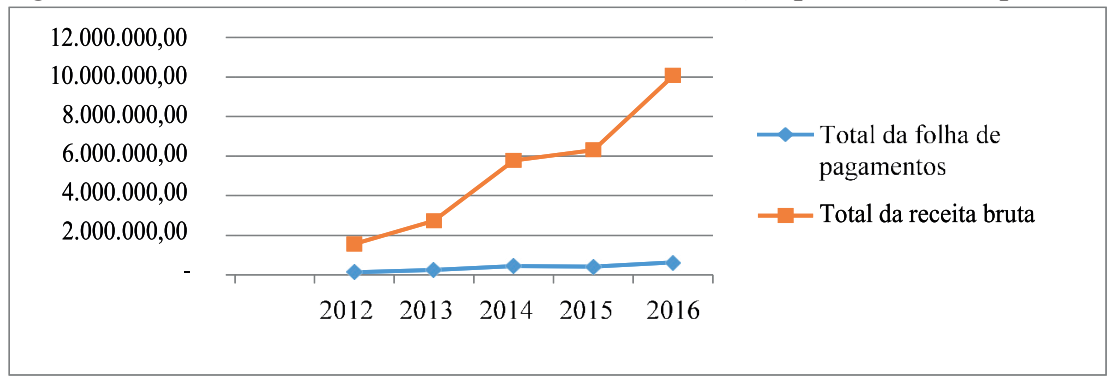

Fonte: Elaborado pelos autores, 2017. 
Afirmam ainda, que o meio mais econômico para o recolhimento da contribuição previdenciária patronal ocorre quando tomado como base de cálculo o total da folha de pagamentos. Evidências encontradas nos documentos e demonstrados no figura 3 .

Figura 3: Total anual da contribuição previdenciária patronal

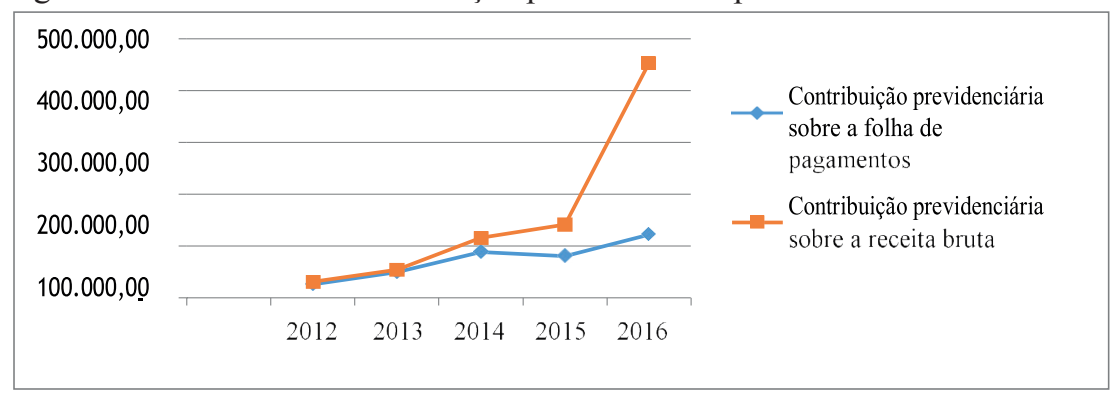

Fonte: Elaborado pelos autores, 2017.

Observa-se que pelo posicionamento dos entrevistados a desoneração da folha de pagamentos não se tornou benéfica para o seguimento deles, conforme já apresentado no Figura 3, mas ao mesmo tempo concordam que para outros pode ser benéfica, corroborando com a pesquisa de Nardelli, Terres e Fidelix (2013) onde constataram que a empresa do ramo pesqueiro analisada teve benefícios com a regulamentação da desoneração da folha de pagamentos.

Em vista do custo com o departamento de pessoal foi possível perceber que ambos os entrevistados desconhecem a sua representatividade quanto ao custo total. Entretanto, ambos afirmam que acreditam que os custos têm aumentado em decorrência do valor dos impostos com a folha de pagamentos, devido ao seu aumento constante.

A redução de custos mediante à aplicação da desoneração da folha de pagamentos é benéfica para empresas que demandam de uma elevada quantia de mão de obra (OLIVEIRA, 2011) e apresentam uma estabilidade no faturamento (RIBEIRO, 2013). Contudo, a construtora objeto de estudo apresenta um cenário oposto ao mencionado, no qual o quadro funcional é relativamente pequeno e o faturamento é instável, o que propiciou o aumento dos custos citados pelos entrevistados.

\subsubsection{Comparativo entre as formas de recolhimento da contribuição previ- denciária patronal}

A empresa objeto de estudo efetuou o recolhimento da contribuição previdenciária pelo modo desonerado até dezembro de 2015. No ano de 2016, devi- 
do à alteração da Lei, optou por efetuar o pagamento da contribuição previdenciária patronal pela folha de pagamentos. Desse modo, este tópico visa efetuar um comparativo entre as formas de recolhimento da contribuição previdenciária patronal sobre o faturamento e sobre a folha de pagamentos.

Ao se analisar o total de recolhimento da contribuição previdenciária patronal anual, por ambas as formas de cálculo, observou-se que a empresa não foi beneficiada pela desoneração da folha de pagamentos nem no vigor da Lei ${ }^{\circ}$ $12.546 / 2011$ nem pela alteração dada pela Lei ${ }^{\circ} 13.161 / 2015$, conforme evidenciado na tabela 1 .

Tabela 1: Comparativo entre as formas de recolhimento da contribuição previdenciária patronal

\begin{tabular}{c|c|c|c|c}
\hline Ano & $\begin{array}{c}\text { Contribuição } \\
\text { previdenciária } \\
\text { patronal sobre } \\
\text { a folha de } \\
\text { pagamentos }\end{array}$ & $\begin{array}{c}\text { Contribuição } \\
\text { previdenciária } \\
\text { patronal sobre } \\
\text { a receita bruta }\end{array}$ & Diferença (\%) & $\begin{array}{c}\text { Desoneração } \\
\text { Vantajosa/ } \\
\text { Desvantajosa }\end{array}$ \\
\hline 2012 & $25.923,26$ & $30.959,59$ & $83,73 \%$ & Desvantajosa \\
\hline 2013 & $49.954,79$ & $54.432,57$ & $91,77 \%$ & Desvantajosa \\
\hline 2014 & $88.528,31$ & $115.660,89$ & $76,54 \%$ & Desvantajosa \\
\hline 2015 & $80.930,47$ & $141.584,78$ & $57,16 \%$ & Desvantajosa \\
\hline 2016 & $122.868,45$ & $453.233,72$ & $27,11 \%$ & Desvantajosa \\
\hline Total & $368.205,30$ & $795.871,55$ & $46,26 \%$ & Desvantajosa \\
\hline
\end{tabular}

Fonte: Elaborado pelos autores (2017)

Neste cenário, evidencia-se que a contribuição previdenciária patronal sobre a folha de pagamentos é o método que gera menor custo com o departamento de pessoal para a entidade, no período delimitado. Conforme afirma Kertzman (2012) tal fato deve-se à estabilidade no total da folha de pagamentos, pois, em regra geral, o faturamento é variável.

É necessário observar que, como no período de 2012 a 2015, a empresa estava obrigada a recolher a contribuição previdenciária patronal pelo método desonerado, a medida promoveu um custo adicional no valor de $\mathrm{R} \$ 97.300,99$, sendo que se calculado a contribuição previdenciária patronal pela folha de pagamentos a empresa teria um custo de $\mathrm{R} \$ 245.336,84$ enquanto que quando calculado pela receita bruta o custo é de $\mathrm{R} \$ 342.637,83$.

No entanto, no ano seguinte, em 2016, devido à alteração da lei, a empresa pode optar por qual método efetuaria o cálculo para o recolhimento da con- 
tribuição previdenciária patronal, e como optante pela base de cálculo da folha de pagamentos, a construtora objeto de estudo teve um custo de $\mathrm{R} \$ 122.868,45$. Sendo que se optante pela desoneração de pagamento o custo teria sido de R $\$$ $453.233,72$, o que gerou uma economia de $\mathrm{R} \$ 330.365,27$.

Ressalta-se que nos anos de 2012 a 2016, houve diferença no total de contribuição previdenciária patronal entre as formas de cálculo, entretanto, a discrepância entre os valores no último ano analisado, deve-se ao aumento na alíquota de $2 \%$ para $4,5 \%$, causado pela alteração da lei. Assim, se a Lei $n^{\circ}$ $13.161 / 2015$ permanecesse obrigando as empresas a optarem pela desoneração da folha de pagamentos, o custo da construtora com a folha de pagamentos seria consideravelmente alto, o que propiciaria a terceirização da mão de obra, conforme medida adotada por uma das empresas analisadas por Ludwig, Borgert e Kremer (2015).

O mesmo resultado obtido nesta pesquisa foi encontrado na pesquisa de Costa, Paixão e Aguiar (2015), na qual os autores verificaram que, em uma das empresas analisadas, a construtora, por ter um quadro de funcionários relativamente pequeno, teve um prejuízo quando do cálculo da contribuição previdenciária patronal sobre a receita bruta.

\subsubsection{Análise da variação do quadro funcional}

Dentre os objetivos da medida da desoneração da folha de pagamentos, está a formalização e criação de novos empregos. Dessa forma, visou-se analisar se na construtora a alteração da legislação pela Lei $n^{\circ}$ 13.161/2015 causou algum reflexo no quadro funcional.

Primeiramente, foi analisado o total de funcionários ativos ao final de cada ano no período de 2012 a 2016, conforme figura 4 .

Figura 4: Total de funcionários ativos ao final do ano

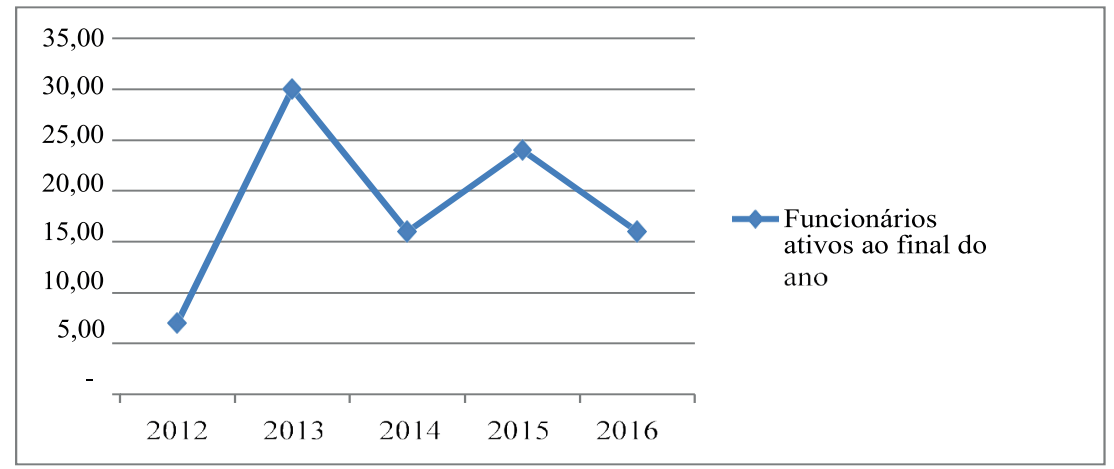

Fonte: Elaborado pelos autores, 2017. 
Inicialmente, percebe-se uma constante oscilação no total anual de funcionários ativos. Sendo que, em 2013, a construtora encerrou o ano com 30 colaboradores, tendo um aumento de $429 \%$ ao comparar com o ano anterior, quando apresentava apenas sete. Posteriormente, em 2014, a empresa apresentou uma queda de $53 \%$ no total de funcionários ativos, a qual foi compensada no ano seguinte, ao apresentar um acréscimo de $67 \%$ no total de colaboradores. Mas, em 2016 a construtora tornou a reduzir o número de colaboradores ativos finalizando o ano com 16 trabalhadores, o que representou uma redução de $67 \%$.

$\mathrm{Na}$ sequência, buscou-se analisar o total de funcionários admitidos e demitidos no período delimitado, conforme apresentado no figura 5 .

Figura 5: Comparativo entre o número de funcionários admitidos e demitidos

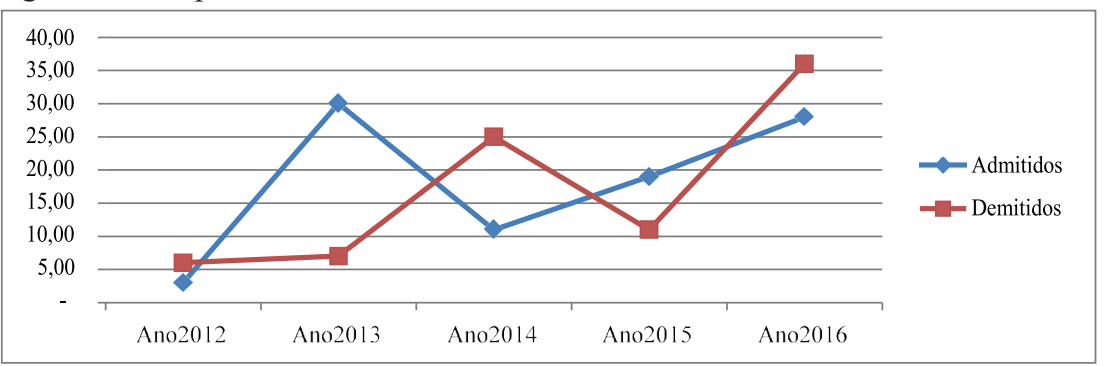

Fonte: Elaborado pelos autores, 2017.

Em 2012, primeiro ano de vigor da legislação da desoneração da folha de pagamentos, o total de funcionários admitidos e demitidos não apresentou disparidade significativa. Entretanto, em 2013 foram admitidos 30 e demitidos sete funcionários, o que fez com que o total de funcionários ativos fosse superior ao ano anterior, conforme apresentado no figura 6.

De 2014 a 2016, o número de admissões aumentou de 11 para 28, diferentemente das demissões que alternaram durante os anos. Sendo que foram demitidos 25 colaboradores em 2014, 11 em 2015 e 36 em 2016. O período em que houve o maior número de demissões foi em 2016, primeiro ano de vigor da Lei $\mathrm{n}^{\circ}$ $13.161 / 2015$. Neste mesmo ano, houve um alto número de contratações, mas que não superaram o total de demissões, o que reduziu o total de funcionários ativos.

Segundo os entrevistados, as admissões ou as demissões não foram motivadas pela regulamentação da desoneração da folha de pagamentos, nem mesmo pelo fator comportamental dos indivíduos, o que interfere neste item é o contrato da obra, conforme apresentado na figura 3. Logo, se a obra for de grandes proporções e exigir um curto período para a concretização, a demanda de mão de obra será superior em relação às de pequenas proporções possibili- 
tando um período maior para a concretização. Fator esse, já contextualizado por Chiavenato (2009), o qual afirma que os colaboradores são considerados apenas ferramentas necessárias à finalização das obras.

Caso semelhante ao apresentado na pesquisa de Ludwig, Borgert e Kremer (2015), os quais concluíram que houve uma evolução no índice de empregabilidade no período estudado, mas que isso não era uma consequência exclusiva à regulamentação da desoneração da folha.

Figura 6: Percepção dos entrevistados em relação aos motivos das admissões e demissões

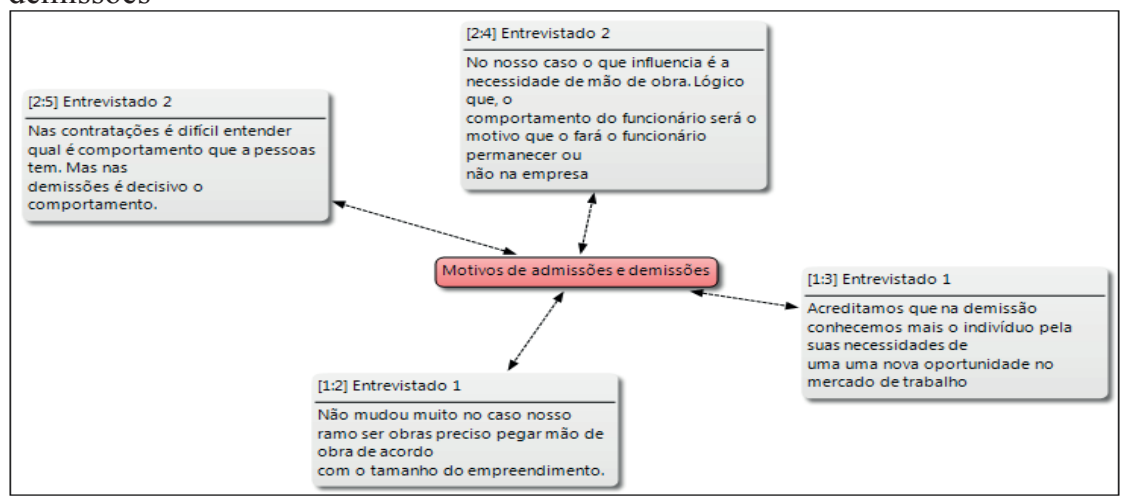

Fonte: Elaborado pelos autores, 2017.

De acordo com o segundo entrevistado, nem sempre é fácil perceber o comportamento da pessoa quando da contratação, somente na execução das tarefas torna-se possível identificar o comportamento do indivíduo, e isso influenciará no desempenho do trabalho. Somente, o período de experiência permite testar as aptidões de prestação de serviço e de convivência com os demais colegas de trabalho. Por meio da fala de um dos entrevistados, ficou evidente que o comportamento é fator importante na manutenção do quadro de funcionários da empresa.

Contudo, a variação do quadro funcional não foi influenciada por nenhum dos motivos destacados nesta pesquisa. Percebe-se, desta forma que o objetivo de formalização e criação de novos empregos proposto pelo Governo Federal com a desoneração da folha de pagamentos, não foi alcançado. Já em relação à Teoria Comportamental, ela pode ser percebida na empresa na gestão de pessoas e na resolução de conflitos internos, entretanto, ela não é a causa das admissões, mas pode ser a causa de algumas demissões. 


\section{CONCLUSÃO}

Por meio do Plano Brasil Maior, o Governo Federal instituiu medidas com o intuito de impulsionar a economia do país. Entre as ações está a Lei ${ }^{\circ}$ 12.546/2011, conhecida como a Lei da desoneração da folha de pagamentos, que tem por objetivo substituir a incidência de contribuição previdenciária patronal de $20 \%$ sobre a folha de pagamentos pela contribuição previdenciária da receita bruta. Mas, esta Lei foi alterada pela Lei $n^{\circ} 13.161 / 2015$ trazendo a possibilidade de opção pela desoneração da folha de pagamentos, também alterou as alíquotas de recolhimento da contribuição previdenciária sobre a receita bruta, com o intuito de reduzir o déficit apresentado pela Previdência Social. Contudo, os objetivos da desoneração da folha de pagamentos para o Governo Federal foram essencialmente a ampliação da competitividade da indústria brasileira, reduzindo o custo do trabalho, estimulando as exportações e o mercado de trabalho formal.

Para a microempresa estudada, identificou-se que a obrigatoriedade da desoneração da folha de pagamentos não foi vantajosa, onerando a empresa, no período de 2012 a 2015, em R \$ 97.300,99. Entretanto, com a alteração da Lei da desoneração da folha de pagamentos pela $13.161 / 2015$, que proporcionou a possibilidade de opção pela desoneração, a empresa economizou R $\$ 330.365,27$, no ano de 2016.

Em relação à variação do quadro funcional, constatou-se que a desoneração da folha de pagamentos não influenciou diretamente, pois o fator determinante é a necessidade de mão de obra para a finalização do serviço. Quanto ao fator comportamental, verificou-se que esse não interfere nas admissões, no entanto, o bom comportamento mantém o colaborador ativo na empresa. Em contrapartida, o comportamento, em desacordo com o esperado pelo gestor, pode ocasionar a demissão sem justa causa antes mesmo do término da obra.

De acordo com o exposto, conclui-se que a desoneração da folha de pagamentos não beneficia empresas que possuem um quadro reduzido de funcionários. A medida foi favorável e proporcionou desenvolvimento para algumas empresas. No entanto, para outras se tornou onerosa. Dessa forma, cabe uma análise de cada situação específica para que a empresa conheça a sua realidade e a administre com eficácia.

Conclui-se que a medida da desoneração da folha de pagamentos onerou a construtora, objeto de estudo, pois a empresa apresenta um quadro de funcionários relativamente pequeno e um faturamento variável, sendo, portanto, a hipótese A, rejeitada. Enquanto que pela análise documental dos relatórios gerados pelo CAGED no período analisado compreendido o período de regulamentação e alteração da desoneração da folha de pagamentos pela Lei 12.546/2011 e a 13.161/2015, constatou-se que houve variação no quadro funcional, entretanto, 
pelos dados obtidos nas entrevistas com o gerente operacional e o responsável do departamento de pessoal, essa variação não ocorreu devido à alteração de lei, sendo, portanto, a hipótese $\mathrm{B}$, válida.

Percebeu-se durante a aplicação da pesquisa que os gestores solicitam anualmente um planejamento tributário aos contadores, tal prática fez com que em 2016, houvesse uma redução de custos com o departamento de pessoal, recomenda-se, portanto que essa prática seja mantida. Sugere-se ainda que os gestores aperfeiçoem a contabilidade gerencial da entidade e invistam na gestão de pessoas com o intuito de promover uma maior satisfação do quadro funcional.

Contudo, a presente pesquisa constatou o que já havia sido evidenciado em estudos anteriores, de que a desoneração da folha de pagamentos onera empresas de pequeno porte do ramo da construção civil. Verificou ainda que, em regra geral, o que influencia na variação do quadro funcional de uma construtora é a necessidade de mão de obra para a conclusão da obra. E por fim, salientou que o comportamento do colaborador o mantém ativo na empresa. Sendo o comportamento em desacordo com o esperado pelos gestores, o contrato será rescindido.

Para verificar se a desoneração efetivamente trouxe benefícios é preciso um estudo acentuado de cada setor desonerado e das particularidades de cada empresa. Por fim, novos estudos podem ser realizados comparando as duas formas de cálculo da contribuição previdenciária patronal em uma empresa de pequeno e uma de grande porte, com o intuito de constatar se o tamanho do quadro funcional interfere no resultado da desoneração da folha de pagamentos.

\section{REFERÊNCIAS}

AMORIN, Lucas. Construção civil vive crise sem precedentes no Brasil. Revista Exame. São Paulo, 2015. Disponível em: http://exame.abril.com.br/revistaexame/a-crise-e-a-crise-da-construcao/. Acesso em: 22 set. 2016.

BAIÃO, T. A nova desoneração da folha de pagamento: Lei 13.161/2015. 2016. Disponível em: https://contadores.cnt.br/noticias/tecnicas/2016/04/14/anova-desoneracao-da-folha-de-pagamento-lei-13-161-2015.html. Acesso em: 01 jul. 2017.

BYROM, K.; BRANDENBURG, S. Strategic management of human resource in construction. Journal of Management in Engineering, Virginia, v. 22, n. 2, p. 8996. Disponível em: http://ascelibrary.org/doi/abs/10.1061/\%28ASCE\%290742597X\%282006\%2922\%3A2\%2889\%29. Acesso em: 02 jul. 2017.

BRASIL, Presidência da república. Constituição da república federativa do 
Brasil, de 1988. Constituição da república federativa do Brasil. Disponível em: http://www.planalto.gov.br/ccivil_03/constituicao/constituicaocompilado. htm. Acesso em: 04 jul. 2017.

Presidência da república. Lei $\mathrm{n}^{0}$ 8.212, de 1991. Organização da seguridade social e plano de custeio. Disponível em: http://www.planalto.gov. br/ccivil_03/leis/L8212cons.htm. Acesso em: 16 jun. 2017.

Presidência da república. Lei ${ }^{0} 8.213$, de 1991. Planos de benefícios da previdência social. Disponível em: < http://www.planalto.gov.br/ccivil_03/ leis/L8213cons.htm>. Acesso em: 08 jul. 2017.

- Presidência da república. Medida Provisória $\mathrm{n}^{0}$ 540, de 2011. Regime especial de reintegração de valores tributários para as empresas exportadoras. Disponível em: http://www.planalto.gov.br/ccivil_03/_ato20112014/2011/mpv/540.htm. Acesso em: 18 jun. 2017.

Presidência da república. Lei $\mathrm{n}^{\circ} 12.546$, de 2011. Regime especial de reintegração de valores tributários para as empresas exportadoras. Disponível em: http:/www.planalto.gov.br/ccivil_03/_ato2011-2014/2011/lei/ 112546.htm. Acesso em: 03 jul. 2016.

. Contribuição previdenciária sobre a receita bruta. Lei $\mathrm{n}^{\circ} 13.161$, de 2015. Desoneração da folha de pagamentos. Disponível em: http://www. normaslegais.com.br/legislacao/lei-13161-2015.htm. Acesso em: 03 jul. 2017.

- Presidência da república. Medida Provisória no 774, de 2017. Contribuição previdenciária sobre a receita bruta. Disponível em: http:// www.planalto.gov.br/ccivil_03/_ato2015-2018/2017/Mpv/mpv774.htm. Aceso em: 07 jul. 2017.

CARVALHÃES, M. A nova desoneração da folha de pagamentos na construção civil com as alterações da Lei 13.161 de 31 de agosto de 2015. 2015. Disponível em: http://blogs.pini.com.br/posts/legislacao-tributos/anova-desoneracao-da-folha-de-pagamento-na-construcao-civil-363963-1.aspx. Acesso em: 05 jul. 2017.

CATALDO, B. Construção civil alinha propostas para retomada da economia. G1, 05 de janeiro de 2016. Disponível em: http:/g1.globo.com/economia/ blog/beth-cataldo/post/construcao-civil-alinha-propostas-para-retomada-daeconomia.html. Acesso em: 22 out. 2016. 
CHIAVENATO, I. Gestão de pessoas. 3 ed. Rio de Janeiro: Elsevier, 2008.

. Recursos humanos: o capital humano das organizações. 9.ed. Rio de Janeiro: Elsevier, 2009.

COSTA, R. L. de S.; PAIXÃO, T. M. S. da; AGUIAR, J. H. S. Impacto da desoneração da folha de pagamento em empreendimentos do munícipio de Salvador. Revista de Iniciação Científica. Cairu, v 2, n. 1, 2015.

FARRAH, M. F. S. Processo de trabalho na construção habitacional: tradição e mudança. São Paulo: Annablume, 1996.

GIL, A. C. Como elaborar projetos de pesquisa. 4. ed. São Paulo: Atlas, 2007.

HEINECK, L. F. M. Efeito aprendizagem, efeito continuidade e efeito concentração no aumento da produtividade nas alvenarias. In: III SIMPÓSIO DE DESEMPRENHO DE MATERIAIS E COMPONENTES DE CONSTRUÇÃO CIVIL, 1991, Florianópolis. Anais... Universidade Federal de Santa Catarina, 1991.

HERNANDES, F. S. Avaliação da produtividade na pré-moldagem das estruturas de concreto armado do viaduto ventenário. Trabalho de conclusão de curso (Graduação em Engenharia Civil). Programa de graduação em Engenharia Civil, Universidade Estadual de Maringá, Maringá, 2002.

INSTITUTO BRASILEIRO DE GEOGRAFIA E ESTATÍSTICA. Pesquisa anual da indústria da construção. Disponível em: ftp://ftp.ibge.gov.br/ Industria_da_Construcao/Pesquisa_Anual_da_Industria_da_Construcao/2012/P AIC2012.pdf. Acesso em: 05 jul. 2017.

KERTZMAN, I. A desoneração da folha de pagamento. LTr, 2012. Disponível em: https://repositorio.ufba.br/ri/browse?type=author\&order=ASC\&rpp=20\&value $=$ Kertzman\%2C+Ivan+Mascarenhas. Acesso em: 25 jun. 2017.

LUDWIG, M. J.; BORGET, A.; KREMER, A. W. O impacto da desoneração da folha de pagamentos no comportamento dos custos das empresas de construção civil. In: VI CONGRESSO UFSC DE CONTROLADORIA E FINANÇAS E INICIAÇÃO CIENTÍFICA EMCONTABILIDADE, 2015, Florianópolis. Anais... Universidade Federal de Santa Catarina, 2015.

MAIA, P. A. Estimativa de exposições não contínuas a ruído: Desenvolvimento 
de um método e validação na Construção Civil. Campinas: 2001. Tese (Doutorado em Engenharia Civil) Universidade Estadual de Campinas. Disponível em: http://www.fundacentro.gov.br/CTN/teses_conteudo.asp?retorno=137. Acesso em: 25/06/2017.

MORAIS, D. M. Briquetes de Resíduos ligno-celulósicos como potencial energético para queima de produtos cerâmicos: Aplicação em uma indústria de cerâmica vermelha que abastece o Distrito Federal. 2007. Tese (Doutorado) Programa de Pós-Graduação em Estrutura e Construção Civil, Universidade de Brasília, Brasília, 2007.

NARDELLI, F. K.; TERRES, J. C.; FIDELIX, L. F. Os reflexos da desoneração da folha de pagamento para fins de contribuição previdenciária: um estudo comparativo entre os setores de indústria e serviço em empresas do Vale do Itajaí/SC. In: V CONGRESSO UFSC DE CONTROLADORIA E FINANÇAS E INICIAÇÃO CIENTÍFICA EM CONTABILIDADE, 2013, Florianópolis. Anais... Universidade Federal de Santa Catarina, 2013.

OLIVEIRA, C. R. Encargos sociais e desoneração da folha de pagamento: revisitando uma antiga polêmica. In: RIBEIRO, J. A. C.; LUCHIEZZI JR, A,; MENDONÇA, S. E. A. (Org.). Progressividade da tributação e desoneração da folha de pagamentos. Brasília: IPEA, 2011. Cap. 4, p. 75-85.

PREVIDÊNCIA SOCIAL. O que é a previdência social. Disponível em: http://www.previdencia.gov.br/acesso-a-informacao/institucional/secretaria-deprevidencia/. Acesso em: 15 jun. 2017.

RECEITA FEDERAL DO BRASIL. Contribuições previdenciárias (pessoas jurídicas). Disponível em: https://idg.receita.fazenda.gov.br/acesso-rapido/ tributos/contribuicoes- previdenciarias-pj. Acesso em: 15 jun. 2017.

RIBEIRO, M. L. Desoneração da folha de pagamento: aspectos que são controversos na contribuição previdenciária substitutiva. $25 \mathrm{f}$. Trabalho de Conclusão de Curso (Graduação em Direito) - Universidade Estadual da Paraíba, Campina Grande, 2013.

ROBINNS, S. P. Comportamento organizacional. São Paulo: Prentice Hall Brasil, 2005.

SKINNER, B. F. Ciência e comportamento humano. 4. ed. São Paulo: Martins Fontes, 1978. 
SPECTOR, P. E. Psicologia nas organizações. 2. ed. São Paulo: Saraiva, 2006.

TAVARES, A.; LONGO, O.; SUETH, R. Conflitos na gestão de pessoas na construção civil. In: XI SIMPÓSIO DE EXCELÊNCIA EM GESTÃO E TECNOLOGIA, 2014, Rio de Janeiro, Anais... 2014.

ZANGHELINI, A. N.; BRAGA, F. R. J.; MAÇANEIRO, V. J. Desoneração da folha de pagamentos: impactos no financiamento da previdência social. Nota técnica Associação Nacional dos Auditores Fiscais da Receita Federal do Brail (ANFIP). 2015. Disponível em: http://www.anfip.org.br/ publicacoes/20150730181429_Nota-Tecnica-Desoneracao-da-Folha-dePagamentos-Impactos-no-Financiamento-da-Previdencia-Social_30-07-2015_ nota_tecnica-FINAL.pdf. A cesso em: 03 jul. 2017. 